\title{
Composição em ácidos graxos e qualidade da carne de tourinhos Nelore e Canchim alimentados com dietas à base de cana-de-açúcar e dois níveis de concentrado ${ }^{1}$
}

\author{
Alexandre Rodrigo Mendes Fernandes ${ }^{2}$, Alexandre Amstalden Moraes Sampaio ${ }^{3}$, Wignez \\ Henrique $^{4}$, Emanuel Almeida de Oliveira ${ }^{5}$, Rodrigo Vidal Oliveira ${ }^{5}$, Fábio Roberto Leonel ${ }^{5}$ \\ 1 Pesquisa financiada pela Fapesp (processo no 06/00841-1). \\ 2 Pós-Doutorando - Departamento de Zootecnia - FCAV/Unesp. Bolsista Fapesp. \\ ${ }^{3}$ Departamento de Zootecnia - FCAV/Unesp. Bolsista CNPq. \\ ${ }^{4}$ APTA - São José do Rio Preto, SP. \\ 5 Pós-Graduação em Zootecnia - FCAV/Unesp. Bolsista CNPq.
}

RESUMO - O objetivo neste trabalho foi avaliar a composição de ácidos graxos e a qualidade do contrafilé (músculo Longissimus lumborum) de tourinhos das raças Nelore e Canchim. Os animais foram terminados em confinamento e alimentados com dietas contendo cana-de-açúcar e dois níveis de concentrado (40 e $60 \%$ na matéria seca). Os concentrados foram compostos de grãos de girassol, milho, farelo de soja, levedura seca de cana-de-açúcar, uréia e núcleo mineral. O delineamento experimental foi o inteiramente ao acaso, em esquema fatorial $2 \times 2$ (grupo genético $\times$ nível de concentrado). Não foram observadas diferenças nos teores de umidade, proteína e extrato etéreo da carne. Os animais da raça Nelore apresentaram maiores concentrações de ácido linoléico conjugado (0,52\%), ácidos graxos insaturados (46,82\%) e também relações mais elevadas de ácidos graxos insaturados:saturados $(1,02)$ e monoinsaturados:saturados $(0,86)$ em comparação aos tourinhos da raça Canchim. Os tourinhos da raça Canchim apresentaram maior intensidade das cores vermelha e amarela no contrafilé e maior luminosidade da gordura de cobertura. Houve interação para força de cisalhamento, que foi menor nos tourinhos Nelore alimentados com $40 \%$ de concentrado. Tourinhos da raça Nelore apresentam carne com melhor composição de ácidos graxos na gordura intramuscular do ponto de vista da saúde humana.

Palavras-chave: ácidos graxos insaturados, ácido linoléico conjugado, cor da carne, força de cisalhamento, grãos de girassol, sabor da carne

\section{Fatty acids composition and meat quality of Nellore and Canchim young bulls fed sugar cane-based diets with two concentrate levels}

\begin{abstract}
The objective of this work was to evaluate the fatty acids composition and the qualitative and chemical characteristics of the loin meat (Longissimus lumborum muscle) of Nellore and Canchim young bulls. The animals were fedlot finished and fed sugar cane-based diets with two concentrate levels (40 and 60\% of dry matter). The concentrates were formulated with sunflower grains, corn, soybean meal, dry sugar cane yeast from sugar and alcohol industry, urea and mineral mixture. The experimental design was a completely randomized design with a $2 \times 2$ factorial arrangement (genetic group $\times$ concentrate level), and the averages were compared by Tukey test at 5\% of probability. Differences were not observed in the humidity, protein and ether extract contents of the loin meat. Nellore bulls had higher concentrations of conjugated linoleic acid $(0.52 \%)$, unsaturated fatty acids $(46.82 \%)$ and higher unsaturated:saturated (1.02), monounsaturated:saturated $(0.86)$ ratios in their loin muscle when compared to Canchim bulls. Canchim bulls presented higher red and yellow color intensity of meat and higher backfat brightness. A significant genetic group $\times$ concentrate level interaction was detected for shear force, where Nellore bulls fed with $40 \%$ of concentrate had lower values. The results showed that Nellore bulls had better fat acid composition of the loin meat, concerning human health.
\end{abstract}

Key Words: conjugated linoleic acid, meat color, meat taste, shear force, sunflower grains, unsaturated fatty acids

\section{Introdução}

A carne bovina é um alimento de elevado valor nutricional, rica em vitaminas do complexo $\mathrm{B}$, minerais essenciais e proteína de alto valor biológico. Entretanto, nos últimos anos, esse alimento tem sido associado ao aumento do índice de colesterol, um fator de risco que colabora para o surgimento de doenças cardiovasculares 
(Scollan et al., 2006). Esse fato está relacionado diretamente às características da gordura presente na carne bovina, que apresenta elevada concentração de ácidos graxos saturados e menor relação entre poliinsaturados e saturados, em comparação à gordura dos animais monogástricos. Essa diferença decorre, principalmente, do processo de biohidrogenação que ocorre no rúmen pela ação de diferentes microrganismos (French et al., 2000).

Além das particularidades relacionadas ao processo digestivo dos ruminantes, Zembayashi et al. (1995) relataram que a raça dos animais, em razão das diferenças associadas à deposição de gordura corporal, apresenta grande influência sobre a composição em ácidos graxos dos lipídios da carne.

Wood et al. (2003) relataram que, nos últimos anos, tem sido crescente o interesse no desenvolvimento de estratégias nutricionais para manipulação da composição de ácidos graxos da carne bovina, estimulado pela necessidade em se produzir uma carne mais saudável, reduzir sua associação a doenças da vida moderna e melhorar a competitividade com as carnes de suínos e aves.

Nesse sentido, French et al. (2000) observaram que o aumento na proporção de forragens frescas na dieta de bovinos proporcionou carne com menor concentração de ácidos graxos saturados, relação mais elevada entre os poliinsaturados:saturados e maior concentração de ácido linoléico conjugado (ALC), reconhecido pelo seu efeito anti-aterogênico. Em outro trabalho, Mir et al. (2003) observaram que os grãos de oleaginosas ricos em ácidos graxos poliinsaturados, como o girassol (Helianthus annuus), podem ser uma alternativa na alimentação dos bovinos visando aumento da síntese de ALC no rúmen, como produto intermediário da hidrogenação do ácido linoléico (C18:2 c9, c12 - $\omega 6$ ), que aparece em grande concentração nesse alimento. Contudo, de acordo com Wood et al. (2003), as alterações na composição de ácidos graxos podem refletir no aroma, no sabor, na coloração e na vida útil da carne, características qualitativas importantes para o consumidor.

Diante dessas observações, objetivou-se avaliar a composição de ácidos graxos e as características qualitativas da carne de tourinhos Nelore e Canchim terminados em confinamento e alimentados com dietas à base de canade-açúcar e dois níveis de concentrado contendo grãos de girassol como fonte de ácidos graxos poliinsaturados.

\section{Material e Métodos}

A terminação dos animais foi realizada no módulo de confinamento do Setor de Bovinocultura de Corte da Faculdade de Ciências Agrárias e Veterinárias/Unesp,
Jaboticabal, São Paulo. Foram utilizados 30 tourinhos: 15 da raça Nelore, com $330 \pm 21 \mathrm{~kg}$ e 18 meses de idade e 15 da raça Canchim, com $300 \pm 24 \mathrm{~kg}$ e 15 meses de idade. A diferenciação de idade e peso inicial dos animais foi proposital e está relacionada às características de crescimento e terminação de cada grupo genético escolhido, permitindo dessa forma, que todos os animais fossem abatidos conjuntamente.

As dietas experimentais foram formuladas visando ganho de peso máximo, de acordo com o sistema CNCPS, desenvolvido por Fox et al. (Tabela 1).

A variedade de cana-de-açúcar utilizada foi a SP 80-1816, que apresenta boa quantidade de sacarose na época de corte (maio a outubro) e não é susceptível a tombamento, facilitando assim a mecanização do corte. A cana-de-açúcar foi colhida e picada diariamente, com auxílio de uma colhedora própria para esta forrageira, regulada para corte de $2 \mathrm{~cm}$ de tamanho de partícula. Os ingredientes utilizados na composição dos concentrados foram triturados em moinho provido de peneira com crivos de $2 \mathrm{~mm}$ e misturados em misturador horizontal por 5 minutos.

Os animais foram pesados, ao final de 105 dias de confinamento após 15 horas de jejum de sólidos, e enviados

Tabela 1 - Composição percentual (em matéria seca) e de ácidos graxos das dietas experimentais

\begin{tabular}{|c|c|c|}
\hline \multirow[t]{2}{*}{ Ingrediente } & \multicolumn{2}{|c|}{ Nível de concentrado } \\
\hline & 40 & 60 \\
\hline Cana-de-açúcar & 60,00 & 40,00 \\
\hline Grãos de girassol & 9,10 & 10,00 \\
\hline Farelo de soja & 7,50 & 7,00 \\
\hline Milho em grão & 17,50 & 28,00 \\
\hline $\begin{array}{l}\text { Levedura seca de usina de } \\
\text { açúcar e álcool }\end{array}$ & 4,40 & 13,80 \\
\hline Núcleo mineral & 0,30 & 0,50 \\
\hline Uréia & 1,00 & 0,40 \\
\hline Bicarbonato de sódio & 0,20 & 0,30 \\
\hline \multicolumn{3}{|l|}{ Composição nutricional } \\
\hline Matéria seca $(\%)$ & 38,59 & 47,54 \\
\hline Proteína bruta (\% MS) & 12,82 & 14,95 \\
\hline Nutrientes digestíveis totais (\% MS) & 69,00 & 74,15 \\
\hline Extrato etéreo (\% MS) & 3,50 & 4,60 \\
\hline Energia metabolizável (MJ/kg MS) & 10,74 & 11,54 \\
\hline Ganho estimado (kg/animal/dia) & 1,0 & 1,3 \\
\hline \multicolumn{3}{|l|}{$\begin{array}{l}\text { Composição de ácidos graxos } \\
\text { (\% dos ácidos graxos totais) }\end{array}$} \\
\hline 14:0 mirístico & 0,24 & 0,30 \\
\hline 16:0 palmítico & 10,21 & 11,22 \\
\hline 16:1 c9 palmitoléico & 0,55 & 0,27 \\
\hline 18:0 esteárico & 4,33 & 4,52 \\
\hline 18:1 c9 oléico & 25,26 & 23,97 \\
\hline 18:2 c9, c12 linoléico & 52,35 & 54,28 \\
\hline 18:3 c9, c12, c15 linolênico & 0,32 & 1,05 \\
\hline 20:0 araquídico & 0,39 & 0,36 \\
\hline
\end{tabular}


a um frigorífico comercial para abate. Os animais Nelore e Canchim apresentaram pesos médios de carcaça quente de 262,06 e $246,78 \mathrm{~kg}$, com cobertura de gordura de 5,5 e $3,2 \mathrm{~mm}$, respectivamente. Com o fornecimento de 40 e $60 \%$ concentrado, foram obtidos pesos de carcaça quente de 244,70 e $265,39 \mathrm{~kg}$, e cobertura de gordura de 4,0 e 4,9 mm, respectivamente. As meias-carcaças foram levadas a câmara fria a $4^{\circ} \mathrm{C}$ por aproximadamente 24 horas.

Todos os procedimentos experimentais, do confinamento ao abate, foram submetidos à apreciação da Comissão de Ética e Bem-Estar Animal (CEBEA) da FCAV/Unesp e receberam aprovação.

Após o resfriamento das carcaças, foi retirada uma seção do músculo Longissimus lumborum, entre a $11^{\mathrm{a}} \mathrm{e} 13^{\mathrm{a}}$ costelas, de cada meia-carcaça esquerda, para as análises laboratoriais. Das amostras foram retiradas cinco fatias do músculo, com aproximadamente $2,5 \mathrm{~cm}$ de espessura; uma para determinação da coloração e da capacidade de retenção de água; uma para avaliação das perdas no cozimento e da força de cisalhamento, conforme descrito por Abularach et al. (1998); outra foi liofilizada para posterior extração do extrato etéreo e análise dos ácidos graxos; e as outras duas restantes foram preparadas para análise sensorial por painel de degustação.

As determinações da cor da carne e da gordura foram realizadas como descrito por Houben et al. (2000), utilizando-se colorímetro e avaliando-se a luminosidade $\left(\mathrm{L}^{*} 0=\right.$ preto; $100=$ branco $)$, a intensidade da cor vermelha $\left(\mathrm{a}^{*}\right) \mathrm{e}$ a intensidade da cor amarela $\left(b^{*}\right)$. Trinta minutos antes das avaliações, em pontos diferentes da amostra da carne, foi realizado um corte transversal ao músculo, para exposição da mioglobina ao oxigênio, conforme descrito por Abularach et al. (1998). A calibração do aparelho foi realizada antes da leitura das amostras com um padrão branco e outro preto.

Após as avaliações de coloração, de cada bife foi retirada uma amostra de aproximadamente $2 \mathrm{~g}$ para determinação da capacidade de retenção de água, obtida por diferença entre os pesos da amostra antes e depois de submetida à pressão de $10 \mathrm{~kg}$, durante 5 minutos, conforme descrito por Hamm (1986).

Para análise da perda de peso no cozimento, as amostras de carne foram assadas em forno a gás a $175^{\circ} \mathrm{C}$ até atingirem $70^{\circ} \mathrm{C}$ no seu centro geométrico. Os pesos dos bifes antes e depois da cocção foram utilizados para os cálculos das perdas totais. Após o resfriamento dos bifes assados, foram retirados seis cilindros de $2 \mathrm{~cm}$ de diâmetro, utilizando-se um vazador, para determinar a força necessária para cortar transversalmente cada cilindro em texturômetro, acoplado à lâmina Warner Bratzler. Foi calculada a média de força de corte dos cilindros para representar a força de cisalhamento de cada bife.

A determinação dos ácidos graxos foi realizada em amostras retiradas do centro do músculo, devidamente acondicionadas in natura em placas de Petri e secas em liofilizador por 48 horas. Após a liofilização, as amostras foram moídas em processador de alimentos com gelo seco para evitar aquecimento e possíveis alterações na composição de ácidos graxos.

A matéria graxa foi extraída com mistura de clorofórmiometanol, segundo Bligh \& Dyer (1959), com as modificações apresentadas por Tullio (2004). Amostras liofilizadas (cerca de $3 \mathrm{~g}$ ) foram transferidas para frascos erlenmeyer de $125 \mathrm{~mL}$, que foram adicionados de $10 \mathrm{~mL}$ de clorofórmio, $20 \mathrm{~mL}$ de metanol e $8 \mathrm{~mL}$ de água destilada e agitados por 30 minutos em mesa agitadora. Após essa operação, foram adicionados $10 \mathrm{~mL}$ de clorofórmio e $10 \mathrm{~mL}$ de sulfato de sódio a $1,5 \%$, e os frascos foram agitados novamente por 2 minutos. O material foi filtrado em papel- filtro quantitativo e transferido para tubos falcon de $50 \mathrm{~mL}$. Após a separação das camadas, a superior, metanóica, foi descartada. Do filtrado restante, $10 \mathrm{~mL}$ foram transferidos para frascos béquer de $50 \mathrm{~mL}$ previamente tarados. Os frascos foram levados para estufa de circulação de ar forçado, a $55^{\circ} \mathrm{C}$, para evaporação do solvente, por 24 horas, e posteriormente foram acondicionados em dessecador para atingirem a temperatura ambiente. Para a transesterificação dos triglicerídeos, aproximadamente $50 \mathrm{mg}$ da matéria lipídica extraída foram transferidos para tubos falcon de $15 \mathrm{~mL}$, aos quais foram adicionados de $2 \mathrm{~mL}$ de $\mathrm{n}$-heptano. A mistura foi agitada até a completa dissolução da matéria graxa e $2 \mathrm{~mL}$ de KOH $2 \mathrm{~mol} / \mathrm{L}$ em metanol foram adicionados. A mistura foi agitada por aproximadamente 5 minutos e após a separação das fases, $1 \mathrm{~mL}$ da fase superior (heptano e ésteres metílicos de ácidos graxos) foi transferido para frascos eppendorf de 1,5 mL. Os frascos foram hermeticamente fechados, protegidos da luz e armazenados em freezer a $-18^{\circ} \mathrm{C}$, para posterior análise cromatográfica.

A composição em ácidos graxos foi determinada por cromatografia gasosa de alta resolução, utilizando-se cromatógrafo a gás, equipado com coluna capilar SP-2560 de $100 \mathrm{~m}$ de comprimento e diâmetro de $0,25 \mathrm{~mm}$, acoplado a um detector de ionização de chama. A temperatura foi programada para iniciar em $130^{\circ} \mathrm{C}$ e foi mantida assim por 1 minuto, quando foi elevada a $170^{\circ} \mathrm{C}$ a $6,5^{\circ} \mathrm{C} /$ minuto. Posteriormente, outra elevação de 170 a $215^{\circ} \mathrm{C}$ foi realizada a $2,75^{\circ} \mathrm{C} /$ minuto e a temperatura foi mantida por 12 minutos. Finalmente, uma última elevação foi realizada de 215 para 
$230^{\circ} \mathrm{Ca} 40^{\circ} \mathrm{C} /$ minuto. As temperaturas do injetor e detector foram de 270 e $280^{\circ} \mathrm{C}$, respectivamente, e as amostras de $0,3 \mathrm{~mL}$ foram injetadas em modo "split" utilizando-se hidrogênio como gás carreador. A identificação dos ésteres metílicos de ácidos graxos foi realizada por comparação com os tempos de retenção e as concentrações dos ácidos graxos de padrões autênticos SIGMA - (fatty acid methyl esters mixtures 189-19), metilados e eluídos nas mesmas condições.

Para a análise sensorial, dois bifes foram assados em forno a gás a $175^{\circ} \mathrm{C}$ até o seu centro geométrico atingir $75^{\circ} \mathrm{C}$, medido por termômetro digital. Após resfriamento, os bifes foram cortados em cubos e servidos a 30 degustadores não treinados. Nesse painel, foram avaliados os atributos sabor, textura, preferência e aparência geral. As notas variaram de 1 a 9 , em que 1 = desaprovação máxima e 9 = aprovação máxima.

Também foram calculados os índices de atividade das enzimas $\Delta^{9}$-dessaturase $\mathrm{C} 16$ e C18, que são responsáveis pela conversão dos ácidos graxos saturados com 16 e 18 átomos de carbono, respectivamente, em seus correspondentes monoinsaturados com dupla ligação no carbono 9, conforme descrito por Malau-Aduli et al. (1997). Esse índice expressa a quantidade do produto (ácido graxo monoinsaturado) como porcentagem do substrato disponível para a conversão e foram obtidos por meio das equações a seguir: $\Delta^{9}$ - Dessat (16) - índice de atividade da enzima dessaturase $\mathrm{C} 16=100(16: 1 / 16: 0+16: 1)$ e $\Delta^{9}$ Dessat (18) - índice de atividade da enzima dessaturase C18=100(18:1/18:0+18:1).

Os resultados obtidos foram submetidos à análise de variância, utilizando-se o procedimento GLM (SAS, 2001), em que o modelo estatístico incluiu os efeitos de grupo genético (Nelore e Canchim), nível de concentrado na dieta (40 e $60 \%$ ) e suas interações. As médias foram comparadas pelo teste de Tukey, considerando o nível de significância de $5 \%$ de probabilidade, quando o teste $\mathrm{F}$ foi significativo para a variável. Para as características sensoriais da carne (sabor, textura, aparência e aspecto geral), foi utilizado o teste não-paramétrico de Kruskal-Wallis, conforme descrito por Sampaio (2002).

\section{Resultados e Discussão}

Não houve efeito significativo $(\mathrm{P}>0,05)$ da interação grupo genético $\times$ nível de concentrado para as variáveis umidade, minerais, extrato etéreo e proteína, assim como do nível de concentrado na dieta. Assim, os dados foram discutidos independentemente considerando somente dos grupos genéticos utilizados.

O grupo genético Canchim apresentou maior $(\mathrm{P}<0,05)$, concentração de minerais nas amostras de contrafilé (Tabela 2) e esse resultado pode estar associado aos pequenos teores de minerais e à pouca variabilidade das repetições. Segundo Lawrie (2004), o teor de extrato etéreo é o que mais varia na carne e, uma vez aumentada sua concentração, ocorre diminuição nas proporções de umidade, proteína e minerais. Conforme relatado por esse autor, a carne bovina possui quase todos os minerais importantes para a nutrição humana e, em termos quantitativos, o fósforo e o potássio são predominantes, seguidos pelo sódio e magnésio. $\mathrm{O}$ ferro presente na carne bovina é absorvido 3 a 5 vezes mais rapidamente que a mesma substância de origem vegetal.

Não houve efeito significativo $(\mathrm{P}>0,05)$ da interação grupo genético $\times$ nível de concentrado sobre os ácidos graxos analisados. Da mesma forma, o nível de concentrado não teve efeito significativo $(\mathrm{P}>0,05)$ para essas variáveis (Tabela 3).

$\mathrm{Na}$ avaliação de grupos genéticos, os tourinhos da raça Nelore apresentaram maiores $(\mathrm{P}<0,05)$ concentrações dos ácidos palmitoléico (C16:1 c9), oléico (C18:1 c9) e linoléico conjugado (C18:2 c9, t11) ALC (Tabela 3). Esse comportamento pode ser explicado pela atividade das enzimas dessaturases.

Os índices de atividade das enzimas dessaturases (C16 e C18) obtidos (Tabela 3 ) indicaram que os animais

Tabela 2 - Composição química do músculo Longissimus lumborum de tourinhos Nelore e Canchim mantidos com dietas à base de canade-açúcar e dois níveis de concentrado

\begin{tabular}{|c|c|c|c|c|c|c|c|}
\hline \multirow[b]{2}{*}{ Variável $^{1}$} & \multicolumn{2}{|c|}{ Grupo genético } & \multirow[b]{2}{*}{$\mathrm{P}^{2}$} & \multicolumn{2}{|c|}{ Nível de concentrado } & \multirow[b]{2}{*}{$\mathrm{P}^{2}$} & \multirow[b]{2}{*}{$\mathrm{CV}(\%)$} \\
\hline & Nelore & Canchim & & 40 & 60 & & \\
\hline Umidade & 73,81 & 74,47 & 0,09 & 74,48 & 73,79 & 0,13 & 1,31 \\
\hline Minerais & 1,09 & 1,16 & 0,02 & 1,13 & 1,12 & 0,83 & 7,22 \\
\hline Extrato etéreo & 2,20 & 2,01 & 0,53 & 1,90 & 2,34 & 0,13 & 26,56 \\
\hline Proteína & 22,90 & 22,80 & 0,78 & 22,75 & 22,95 & 0,83 & 4,84 \\
\hline
\end{tabular}

${ }^{1}$ Valores expressos em porcentagem do músculo Longissimus lumborum (contrafilé).

${ }^{2} \mathrm{P}$ - Probabilidade; CV - coeficiente de variação. 
Tabela 3 - Composição de ácidos graxos e índices de atividade das enzimas dessaturases do músculo Longissimus lumborum de tourinhos Nelore e Canchim mantidos com dietas à base de cana-de-açúcar e dois níveis de concentrado

\begin{tabular}{|c|c|c|c|c|c|c|c|}
\hline \multirow[b]{2}{*}{ Ácido graxo (\%) } & \multicolumn{2}{|c|}{ Grupo genético } & \multirow[b]{2}{*}{$\mathrm{P}^{1}$} & \multicolumn{2}{|c|}{ Nível de concentrado } & \multirow[b]{2}{*}{$\mathrm{P}^{1}$} & \multirow[b]{2}{*}{$\mathrm{CV}(\%)$} \\
\hline & Nelore & Canchim & & 40 & 60 & & \\
\hline $14: 0$ & 4,39 & 4,26 & 0,83 & 4,12 & 4,55 & 0,54 & 43,17 \\
\hline \multicolumn{8}{|l|}{ Mirístico } \\
\hline \multirow{2}{*}{\multicolumn{8}{|c|}{ Miristoléico }} \\
\hline & & & & & & & \\
\hline $15: 0$ & 0,45 & 0,57 & 0,03 & 0,53 & 0,48 & 0,28 & 27,10 \\
\hline \multicolumn{8}{|l|}{ Pentadecanóico } \\
\hline $16: 0$ & 26,11 & 26,59 & 0,69 & 26,41 & 26,26 & 0,90 & 12,46 \\
\hline \multicolumn{8}{|l|}{ Palmítico } \\
\hline $16: 1$ c9 & 3,56 & 2,76 & $<0,01$ & 3,11 & 3,24 & 0,64 & 23,34 \\
\hline \multicolumn{8}{|l|}{ Palmitoléico } \\
\hline $17: 0$ & 0,79 & 0,85 & 0,15 & 0,81 & 0,83 & 0,59 & 13,15 \\
\hline \multicolumn{8}{|l|}{ Heptadecanóico } \\
\hline $18: 0$ & 14,32 & 16,21 & 0,04 & 15,23 & 15,23 & 0,99 & 15,42 \\
\hline \multicolumn{8}{|l|}{ Esteárico } \\
\hline $18: 1$ c9 & 34,84 & 29,67 & $<0,01$ & 32,10 & 32,61 & 0,68 & 10,68 \\
\hline \multicolumn{8}{|l|}{ Oléico } \\
\hline $18: 2 \mathrm{c} 9, \mathrm{c} 12$ & 5,51 & 5,98 & 0,52 & 6,18 & 5,26 & 0,24 & 36,57 \\
\hline \multicolumn{8}{|l|}{ Linoléico } \\
\hline $18: 3 \mathrm{c} 9, \mathrm{c} 12, \mathrm{c} 15$ & 0,26 & 0,24 & 0,49 & 0,25 & 0,25 & 0,76 & 29,77 \\
\hline \multicolumn{8}{|l|}{ Linolênico } \\
\hline $18: 2 \mathrm{c} 9, \mathrm{t} 11 \mathrm{ALC}$ & 0,52 & 0,41 & 0,01 & 0,46 & 0,47 & 0,79 & 25,14 \\
\hline $20: 3$ c 8, c 11, c14 & 1,00 & 1,03 & 0,89 & 1,16 & 0,86 & 0,25 & 68,80 \\
\hline \multicolumn{8}{|l|}{ Eicosatrienóico } \\
\hline $22: 0$ & 0,29 & 0,26 & 0,41 & 0,28 & 0,28 & 0,93 & 30,69 \\
\hline \multicolumn{8}{|l|}{ Behênico } \\
\hline $14: 0+16: 0$ & 30,50 & 30,85 & 0,85 & 30,54 & 30,82 & 0,88 & 16,28 \\
\hline \multicolumn{8}{|l|}{ Mirístico+Palmítico } \\
\hline$\Delta^{9}-$ Dessat $(16)^{2}$ & 12,11 & 9,87 & $<0,01$ & 11,12 & 11,12 & 0,24 & 12,68 \\
\hline$\Delta^{9}-$ Dessat $(18)^{3}$ & 70,88 & 66,44 & $<0,01$ & 68,61 & 62,22 & 0,22 & 12,98 \\
\hline
\end{tabular}

${ }^{1} \mathrm{P}$ - Probabilidade; $\mathrm{CV}$ - coeficiente de variação.

${ }^{2} \Delta$ 9. Dessat (16) - índice de atividade da enzima dessaturase $\mathrm{C} 16=100(16: 1 / 16: 0+16: 1)$.

${ }^{3} \Delta^{9}$ - Dessat (18) - índice de atividade da enzima dessaturase $\mathrm{C} 18=100(18: 1 / 18: 0+18: 1)$.

da raça Nelore apresentaram maior $(\mathrm{P}<0,05)$ atuação da $\Delta{ }^{9}$-dessaturase no músculo Longissimus lumborum que os tourinhos Canchim, uma vez que os teores de C16:1 c9, C18:1 c9 e ALC foram semelhantes nos dois níveis de concentrado estudados. Segundo Malau-Aduli et al. (1997) e Beaulieu et al. (2002), essa enzima é responsável pela dessaturação dos ácidos graxos saturados com 16 e 18 carbonos, convertendo-os em seus correspondentes monoinsaturados, com ligação dupla no carbono 9. A produção do ALC pela $\Delta{ }^{9}$-Dessaturase é realizada a partir do ácido trans vacênico (C18:1 t11), produzido pela biohidrogenação incompleta dos ácidos linoléico e linolênico pelas bactérias ruminais. Conforme relatado pelos mesmos autores, essa enzima apresenta atuação no epitélio do intestino e tecido muscular, porém em menor intensidade que no tecido adiposo, e sua atividade pode ser influenciada pela raça, pela idade, pelo sexo e pelo grau de maturidade fisiológica dos animais.

O C18:1, c9, reconhecido por seu efeito hipocolesterolêmico, foi o ácido graxo monoinsaturado (AGMI) predo- minante, assim como observado por Scollan et al. (2006). Os efeitos do $\mathrm{C} 16: 1 \mathrm{c} 9$, no entanto, não foram ainda identificados com precisão pela comunidade científica, mas, aparentemente, não possui atuação no metabolismo hepático das lipoproteínas de baixa densidade (low density lipoprotein - LDL).

Fernandes (2007) trabalhou com tourinhos, novilhos e novilhas da raça Canchim e observou aumento de $0,34 \%$ para $0,73 \%$ na concentração de ácido linoléico conjugado quando substituiu a alimentação convencional à base de silagem de milho e concentrado por cana-de-açúcar e concentrado contendo grãos de girassol. Provavelmente, esse resultado esteve associado à variedade de cana-deaçúcar forrageira IAC 86-2480 utilizada por esse autor, em comparação à variedade industrial SP 80-1816 utilizada neste estudo. Segundo Freitas et al. (2006), a variedade SP 80-1816 possui superioridade de $14 \%$ no teor de lignina em relação a IAC 86-2480, o que pode piorar a digestão dos carboidratos da parede celular e aumentar o tempo de retenção da digesta no rúmen. Provavelmente houve tempo 
necessário para que os microrganismos pudessem atuar de maneira completa na saturação do ácido linoléico (C18:2 c9,c12), diminuindo a quantidade de ácido linoléico conjugado disponível para absorção intestinal, uma vez que este produto é o primeiro intermediário no processo de biohidrogenação.

Padre et al. (2006) trabalharam com tourinhos e novilhos Angus terminados em pastagens e observaram valores de ALC de $0,13 \times 0,45 \%$, respectivamente. Os valores encontrados neste trabalho foram superiores aos descritos por esses autores, em razão da menor concentração do ácido linoléico (C18:2 c9, c12) no pasto, diminuindo a síntese de ácido linoléico conjugado pelas bactérias ruminais por insuficiência do principal substrato. Em contrapartida, neste trabalho, os teores de ácido linolênico (C18:3 c9, c12, c15) na carne foram menores, o que pode ser justificado pela concentração de ácidos graxos na forma de C18:3 c9, c12, c15, entre 50 e $65 \%$ em forragens frescas (Scollan et al., 2006).

De La Torre et al. (2006) relataram que a taxa de deposição de ALC não depende da quantidade final de gordura corporal dos animais, mas é favorecida com o fornecimento de ácidos graxos insaturados na alimentação dos animais, mesmo em condições de menor taxa de deposição de gordura, normalmente observada em animais jovens como os deste presente trabalho.

As maiores concentrações $(\mathrm{P}<0,05)$ dos ácidos pentadecanóico (C15:0) e esteárico (C18:0) foram obtidas nas amostras de contrafilé dos animais do grupo genético Canchim (Tabela 3). Os ácidos graxos de cadeia ímpar são raros nos tecidos da maioria dos mamíferos, mas aparecem em porcentagem considerável nos ruminantes e não podem ser relacionados ao nível de colesterol. Mansbridge \& Blake (1997) relataram que o C15:0 e o heptadecanóico (C17:0) são provenientes da síntese de novo pelas bactérias ruminais, a partir do propionato $(\mathrm{C} 3: 0)$ e posteriormente incorporados nos lipídios microbianos. Os lipídios originários dos microrganismos podem representar $10 \mathrm{a}$ $15 \%$ do total que chega ao intestino delgado.
Ao contrário dos ácidos graxos saturados mirístico (C14:0) e palmítico (C16:0), considerados os mais hipercolesterolêmicos, por diminuírem a atividade dos receptores hepáticos da LDL, o C18:0, que pode variar de 10 a $20 \%$ da gordura dos ruminantes, é considerado neutro, conforme observado por Scollan et al. (2006).

Segundo Bessa (1999), seria necessária a introdução e difusão de um critério de agrupamento dos ácidos graxos pelas características funcionais (hipocolesterolêmico, neutro e hipercolesterolêmico) e não apenas pela estrutura da molécula (saturados e insaturados), o que muitas vezes pode acarretar em erros de avaliação nutricional dos alimentos. Conforme esse autor, essa classificação proposta poderia colocar a carne bovina em evidência como um alimento funcional. Neste estudo, apenas 30\% dos ácidos graxos encontrados na carne dos animais, ou seja, a somatória de C14:0 + C16:0, seriam potencialmente relacionados ao aumento do colesterol em humanos. Em contrapartida, foram observados valores elevados de outros ácidos graxos reconhecidos pelos efeitos benéficos à saúde humana, como os ácidos oléico (18:1 c9), linoléico (18:2 c9, c12), linolênico (18:3 c9, c12, c15) e o ALC (18:2 c9, t11).

Não houve interação significativa $(\mathrm{P}>0,05)$ entre grupo genético e nível de concentrado (Tabela 4) para as concentrações totais de ácidos saturados (AGS), insaturados (AGI), monoinsaturados (AGMI) e também para as relações insturados:saturados (AGI:AGS), monoinsaturados: saturados (AGMI:AGS) e poliinsturados:saturados (AGPI:AGS). Os níveis de concentrado avaliados também não tiveram efeitos significativos $(\mathrm{P}>0,05)$ sobre as concentrações desses ácidos graxos (Tabela 4).

O músculo Longissimus lumborum dos tourinhos Nelore apresentou maiores $(\mathrm{P}<0,05)$ concentrações de AGI, AGMI e também maiores relações AGI:AGS e AGMI:AGS em relação aos animais da raça Canchim. Esses resultados são reflexo da superioridade de 29 e $17 \%$ dos teores de C16:1 c9 e C18:1 c9, respectivamente, encontrados no músculo dos animais Nelore, em razão da ação das

Tabela 4 - Concentração de ácidos graxos no músculo Longissimus lumborum de tourinhos Nelore e Canchim mantidos com dietas à base de cana-de-açúcar e dois níveis de concentrado

\begin{tabular}{|c|c|c|c|c|c|c|c|}
\hline \multirow[b]{2}{*}{ Ácido graxo (\%) } & \multicolumn{2}{|c|}{ Grupo genético } & \multirow[b]{2}{*}{$\mathrm{P}^{1}$} & \multicolumn{2}{|c|}{ Nível de concentrado } & \multirow[b]{2}{*}{$\mathrm{P}^{1}$} & \multirow[b]{2}{*}{$\mathrm{CV}(\%)$} \\
\hline & Nelore & Canchim & & 40 & 60 & & \\
\hline Saturados & 46,37 & 48,76 & 0,17 & 47,41 & 47,65 & 0,88 & 9,51 \\
\hline Insaturados & 46,82 & 40,86 & $<0,01$ & 44,18 & 43,69 & 0,76 & 9,99 \\
\hline Monoinsaturados & 39,52 & 33,20 & $<0,01$ & 36,12 & 36,84 & 0,55 & 8,92 \\
\hline Poliinsaturados & 7,30 & 7,60 & 0,70 & 8,06 & 6,85 & 0,25 & 37,12 \\
\hline Relação insaturados:saturados & 1,02 & 0,85 & 0,01 & 0,94 & 0,93 & 0,77 & 17,97 \\
\hline Relação monoinsaturados:saturados & 0,86 & 0,68 & $<0,01$ & 0,77 & 0,78 & 0,82 & 14,74 \\
\hline Relação poliinsaturados:saturados & 0,16 & 0,16 & 0,94 & 0,17 & 0,14 & 0,32 & 46,15 \\
\hline
\end{tabular}

${ }^{1} \mathrm{P}$ - Probabilidade; CV - coeficiente de variação. 
enzimas dessaturases nos ácidos graxos de 16 e 18 carbonos, como comentado anteriormente (Tabela 3). A relação AGPI:AGS foi inferior à preconizada pelo Departamento de Saúde do Reino Unido, que recomenda valor aproximado de 0,4 ; caracterizando, dessa forma, uma dieta mais saudável (Wood et al., 2003).

French et al. (2000) observaram que, com a diminuição da proporção de concentrado na dieta e aumento da participação de forragem, houve diminuição linear de ácidos graxos saturados. Os autores encontraram maiores concentrações de AGPI em animais mantidos em pastagens e aumento linear na relação AGPI:AGS com a diminuição da ingestão de concentrados em dietas com forragem fresca, e atribuíram esses resultados à maior ingestão de ácidos graxos insaturados provenientes da forragem. Tullio (2004) também observou maiores concentrações de AGPI e maior relação AGPI:AGS na carne de animais terminados no pasto em relação aos confinados.

Não houve interação significativa $(\mathrm{P}>0,05)$ grupo genético $\times$ nível de concentrado para a qualidade da carne (Tabela 5). Foram observados maiores valores $(\mathrm{P}<0,05)$ de capacidade de retenção de água $(\mathrm{CRA})$ e menores $(\mathrm{P}<0,05)$ perdas totais no cozimento (PTC) nas amostras provenientes dos animais mantidos com a dieta contendo $40 \%$ de concentrado. A carne dos animais da raça Canchim apresentou maiores $(\mathrm{P}<0,05)$ valores de intensidade de vermelho $\left(\mathrm{a}^{*}\right)$ e amarelo $\left(\mathrm{b}^{*}\right)$ no músculo Longissimus lumborum. O valor de $\mathrm{pH}$ e a luminosidade $\left(\mathrm{L}^{*}\right)$ da gordura de cobertura foram maiores $(\mathrm{P}<0,05)$ nas amostras dos tourinhos Nelore.

Segundo Lawrie (2004), a formação de ácido lático e a redução do $\mathrm{pH}$ são responsáveis pela diminuição da capacidade da carne em reter água durante a aplicação de forças como cortes e aquecimento. Em pH 5,2-5,3 (ponto isoelétrico das proteínas musculares, com equilíbrio de cargas positivas e negativas), a carne apresenta menor capacidade de retenção de água. Em pH acima de 5,5 existe excesso de cargas negativas que determinam repulsão dos filamentos protéicos, deixando maior espaço para as moléculas de água e reduzindo a força mecânica necessária para o corte e as perdas durante o cozimento.

Conforme descrito por Abularach et al. (1998), valores de $\mathrm{pH}$ entre 5,4 e 5,6 são considerados normais para a carne bovina. Dessa forma, o músculo Longissimus lumborum proveniente dos animais da raça Canchim esteve dentro dos padrões aceitáveis e esse resultado contribuiu para as maiores intensidades de $\mathrm{a}^{*} \mathrm{e} \mathrm{b}^{*}$ da carne. Carnes com $\mathrm{pH}$ acima de 6,0, como no caso dos tourinhos Nelore, podem apresentar aspecto escuro ou DFD (dark, firm and dry). Quando avaliados os níveis de concentrado, foi possível observar que os valores (Tabela 5) permaneceram acima dos ideais $(5,7-5,8)$ e, nesse ponto, a carne pode apresentar maior retenção de água e menor vida de prateleira.

A ocorrência de carne DFD está associada a condições inadequadas de manejo dos animais e estresse pré-abate e, de acordo com Gregory (1998), tourinhos mantidos em confinamento são mais susceptíveis ao estresse que animais criados extensivamente, o que contribui para que a redução do $\mathrm{pH}$ após o resfriamento não seja efetiva. Animais submetidos a condições de estresse apresentam maior consumo de glicogênio muscular antes do abate e, assim, a produção de ácido lático pela degradação do glicogênio, responsável pela redução do pH, é menor.

A análise combinatória dos resultados de $\mathrm{pH}$, capacidade de retenção de água e perdas totais no cozimento podem justificar a interação significativa e a menor força de

Tabela 5 - Valores de pH, capacidade de retenção de água, perdas totais no cozimento e características de cor da carne e da gordura do músculo Longissimus lumborum de tourinhos Nelore e Canchim, mantidos com dietas à base de cana-de-açúcar e dois níveis de concentrado

\begin{tabular}{|c|c|c|c|c|c|c|c|}
\hline \multirow[b]{2}{*}{ Variável } & \multicolumn{2}{|c|}{ Grupo genético } & \multirow[b]{2}{*}{$\mathrm{P}^{1}$} & \multicolumn{2}{|c|}{ Nível de concentrado } & \multirow[b]{2}{*}{$\mathrm{P}^{1}$} & \multirow[b]{2}{*}{$\mathrm{CV}(\%)$} \\
\hline & Nelore & Canchim & & 40 & 60 & & \\
\hline $\mathrm{pH}$ & 6,16 & 5,59 & $<0,01$ & 5,96 & 5,80 & 0,16 & 4,63 \\
\hline Capacidade de retenção de água, \% & 73,39 & 73,21 & 0,88 & 74,23 & 72,31 & 0,02 & 2,97 \\
\hline Perdas totais no cozimento, $\%$ & 26,60 & 26,79 & 0,87 & 25,76 & 27,68 & 0,02 & 8,15 \\
\hline \multicolumn{8}{|l|}{ Carne } \\
\hline Luminosidade & 31,31 & 36,84 & 0,82 & 34,20 & 33,73 & 0,20 & 17,14 \\
\hline Intensidade da cor vermelha & 12,91 & 15,03 & $<0,01$ & 13,83 & 14,05 & 0,74 & 12,80 \\
\hline Intensidade da cor amarela & 3,36 & 5,41 & $<0,01$ & 4,36 & 4,33 & 0,95 & 28,65 \\
\hline \multicolumn{8}{|l|}{ Gordura } \\
\hline Luminosidade & 72,5 & 69,74 & $<0,01$ & 71,49 & 70,83 & 0,44 & 3,27 \\
\hline Intensidade da cor vermelha & 4,76 & 5,92 & 0,18 & 5,02 & 5,65 & 0,45 & 41,87 \\
\hline Intensidade da cor amarela & 8,45 & 9,48 & 0,10 & 9,20 & 8,68 & 0,40 & 18,63 \\
\hline
\end{tabular}

${ }^{1} \mathrm{P}$ - Probabilidade; CV - coeficiente de variação. 
cisalhamento da carne dos tourinhos Nelore em relação aos animais Canchim, alimentados com $40 \%$ de concentrado (Tabela 6).

Os valores de força de cisalhamento neste trabalho foram inferiores aos descritos por Abularach et al. (1998), que obtiveram média de $6,70 \mathrm{~kg} / \mathrm{cm}^{2}$ para animais Nelore abatidos com 23 a 29 meses de idade. No trabalho de Restle et al. (2001), o valor médio obtido para novilhas $3 / 4$ Charolês $\times 1 / 4$ Nelore foi de $6,24 \mathrm{~kg} / \mathrm{cm}^{2}$. Valores de força de cisalhamento abaixo de $4,00 \mathrm{~kg} / \mathrm{cm}^{2}$ foram obtidos por Brondani et al. (2006), que avaliaram a carne de bovinos Angus e Hereford com idade próxima a 13 meses e ressaltaram que a força de cisalhamento depende de fatores como idade dos animais e grau de marmoreio. Lawrie (2004) observou que valores abaixo de $5,00 \mathrm{~kg} / \mathrm{cm}^{2}$ caracterizam a carne como macia.

Segundo Rubensam et al. (1998), valores elevados de força de cisalhamento são comuns em animais zebuínos e essa característica possivelmente está associada a maior atividade da enzima calpastatina, que possui efeito inibidor sobre as calpaínas, responsáveis pela proteólise postmortem e, portanto, pelo amaciamento da carne. Segundo Lawrie (2004), outros fatores como a idade do animal e a cobertura de gordura da carcaça são determinantes sobre essa característica. Animais mais velhos apresentam estruturas de colágeno e elastina mais insolúveis e carcaças com cobertura de gordura inadequada são mais susceptíveis ao encurtamento das fibras musculares durante o resfriamento (cold-shortening), fatores que implicam diretamente na ausência de maciez da carne.

Neste estudo foram avaliados animais jovens, com idade ao abate inferior a 22 meses. Entretanto, os tourinhos Canchim apresentaram espessura de gordura em torno de $3 \mathrm{~mm}$, o que pode ter prejudicado a proteção da carcaça contra os efeitos negativos do resfriamento, principalmente no contrafilé, que, por ser um corte mais externo da carcaça, pode ser mais susceptível ao encurtamento de fibras pelo frio. O acabamento de carcaças dos tourinhos Nelore permaneceu acima dos $5 \mathrm{~mm}$ e houve maior homogeneidade na distribuição da gordura sobre a carcaça. Dessa forma, outros fatores interferiram de maneira mais significativa na maciez e tiveram efeitos mais pronunciados que o complexo enzimático do músculo.

Não foram observados efeitos $(\mathrm{P}>0,05)$ de grupo genético e nível de concentrado para as características sensoriais, nem da interação grupo genético $\times \operatorname{dieta}(\mathrm{P}>0,05)$ (Tabela 7).

O sabor das carnes vermelhas, segundo Scollan et al. (2006), é derivado da reação de Maillard entre aminoácidos e açúcares redutores e também da degradação lipídica pelo efeito do aquecimento. Assim, as alterações na composição dos ácidos graxos podem alterar a quantidade e os tipos de compostos voláteis produzidos durante o preparo da carne, modificando o aroma e o sabor. Zembayashi et al. (1995) ressaltaram que o contrafilé com maior porcentagem de C18:1 c9 geralmente apresenta maiores pontuações quando avaliados em painel sensorial, o que não foi observado neste estudo.

Fernandes (2007) observou que a carne de novilhas Canchim recebeu melhor pontuação no quesito sabor em relação a tourinhos e novilhos da mesma raça, com superioridade de 15 e $6 \%$ para o teor de C18:1 c9 da carne das novilhas em relação às amostras de tourinhos e novilhos, respectivamente.

É possível observar que os resultados do painel sensorial (Tabela 7) obtidos para textura não acompanharam os da análise realizada pelo texturômetro (força de cisalhamento) (Tabela 6). Segundo descrito por Lawrie (2004), a base dos métodos mecânicos de avaliação é a força de corte, ou seja, uma medida objetiva. A impressão da textura na avaliação sensorial envolve a facilidade da penetração dos dentes na carne e da sua desintegração na boca e a quantidade de resíduo após a mastigação, o que torna essa análise muito mais complexa e, muitas vezes, dificulta a correlação entre as avaliações.

Tabela 6 - Força de cisalhamento $\left(\mathrm{kg} / \mathrm{cm}^{2}\right)$ do músculo Longissimus lumborum de tourinhos Nelore e Canchim mantidos com dietas à base de cana-de-açúcar e dois níveis de concentrado

\begin{tabular}{|c|c|c|c|c|c|}
\hline \multirow[b]{3}{*}{ Grupo genético } & \multicolumn{2}{|c|}{ Nível de concentrado } & \multirow[b]{3}{*}{ Média } & \multirow[b]{3}{*}{$\mathrm{P}^{1}$} & \multirow[b]{3}{*}{$\mathrm{CV}(\%)$} \\
\hline & 40 & 60 & & & \\
\hline & \multicolumn{2}{|c|}{ Força de cisalhamento } & & & \\
\hline Nelore & $3,07 \mathrm{Bb}$ & $4,67 \mathrm{Aa}$ & 3,87 & 0,01 & 22,56 \\
\hline Canchim & $5,11 \mathrm{Aa}$ & $4,87 \mathrm{Aa}$ & 4,99 & & \\
\hline Média & 4,09 & 4,77 & - & & \\
\hline
\end{tabular}

Médias seguidas por letras diferentes, na coluna (maiúsculas) e na linha (minúsculas), diferem pelo teste Tukey a 5\% de probabilidade.

${ }^{1} \mathrm{P}$ - Probabilidade; CV - coeficiente de variação. 
Tabela 7 - Análise sensorial da carne do músculo Longissimus lumborum de tourinhos Nelore e Canchim mantidos com dietas à base de cana-de-açúcar e dois níveis de concentrado

\begin{tabular}{|c|c|c|c|c|c|c|c|}
\hline \multirow[b]{2}{*}{ Variável $^{1}$} & \multicolumn{2}{|c|}{ Grupo genético } & \multirow[b]{2}{*}{$\mathrm{P}^{2}$} & \multicolumn{2}{|c|}{ Nível de concentrado } & \multirow[b]{2}{*}{$\mathrm{P}^{2}$} & \multirow[b]{2}{*}{$\mathrm{CV}(\%)$} \\
\hline & Nelore & Canchim & & 40 & 60 & & \\
\hline Sabor & 7,0 & 7,1 & 0,64 & 7,1 & 7,1 & 0,94 & 21,91 \\
\hline Textura & 6,8 & 7,2 & 0,29 & 6,9 & 7,2 & 0,35 & 23,65 \\
\hline Aspecto geral & 6,8 & 7,2 & 0,16 & 6,9 & 7,1 & 0,39 & 20,88 \\
\hline Preferência & 6,7 & 7,3 & 0,08 & 7,0 & 7,0 & 0,94 & 23,31 \\
\hline
\end{tabular}

${ }^{1}$ Notas atribuídas por painel de degustação; 9 - aprovação máxima; 1 - desaprovação máxima.

$2 \mathrm{P}$ - Probabilidade; CV - coeficiente de variação.

De modo geral, pelas notas atribuídas, a carne apresentou boas características de textura e sabor. Provavelmente, os quesitos aspecto geral e preferência foram influenciados negativamente no grupo genético Nelore, pelos valores de $\mathrm{pH}$ e características de coloração da carne (Tabela 5).

\section{Conclusões}

Níveis de concentrado de 40 e $60 \%$ na matéria seca da dieta não promoveram diferenças na composição em ácidos graxos e nas características qualitativas da carne. Tourinhos da raça Nelore apresentam carne com melhor composição em ácidos graxos do ponto de vista da saúde humana, enquanto tourinhos Canchim apresentam carne com coloração mais atrativa para o consumidor.

\section{Agradecimentos}

À Usina São Martinho, pela doação da levedura seca utilizada na composição dos concentrados.

\section{Literatura Citada}

ABULARACH, M.L.; ROCHA, C.E.; FELÍCIO, P.E. Características de qualidade do contra-filé (m. L. dorsi) de touros jovens da raça Nelore. Ciência e Tecnologia de Alimentos, v.18, n.2, p.205-210, 1998

BEAULIEU, A.D.; DRACKLEY, J.K.; MERCHEN, N.R. Concentrations of conjugated linoleic acid (cis-9, trans-11 octadienoic acid) are not increased in tissue lipids of cattle fed with high concentrate died supplemented with soybean oil. Journal of Animal Science, v.80, n.3, p.847-861, 2002.

BESSA, R.J.B. Revalorização nutricional das gorduras dos ruminantes. In: SYMPOSIUM EUROPEO - ALIMENTACIÓN EM EL SIGLO, 31., 1999, Badajoz. Anais... Badajoz: Colégio Oficial de Veterinarios de Badajoz, 1999. p.283-313.

BLIGH, E.G.; DYER, W.J. A rapid method of total lipid extraction and purification. Canadian Journal of Biochemistry and Physiology, v.37, p.911-917, 1959.

BRONDANI, I.L.; SAMPAIO, A.A.M.; RESTLE, J. Composição física da carcaça e aspectos qualitativos da carne de bovinos de diferentes raças alimentados com diferentes níveis de energia. Revista Brasileira de Zootecnia, v.35, n.5, p.2034-2042, 2006.
DE LA TORRE, A.; GRUFFAT, D.; DURAND, D. et al. Factors influencing proportion and composition of CLA in beef. Meat Science, v.73, n.2, p.258-268, 2006.

FERNANDES, A.R.M. Eficiência produtiva e características qualitativas da carne de bovinos Canchim terminados em confinamento. 2007. 117f. Tese (Doutorado em Zootecnia) - Faculdade de Ciências Agrárias e Veterinárias, Universidade Estadual Paulista, Jaboticabal, 2007.

FREITAS, A.W.P.; PEREIRA, J.C.; ROCHA, F.C. et al. Avaliação da divergência nutricional de genótipos de cana-de-açúcar (Saccharum spp). Revista Brasileira de Zootecnia, v.35, n.1, p.229-236, 2006.

FRENCH P.; STANTON, C.; LAWLESS, F. et al. Fatty acid composition, including conjugated linoleic acid, of intramuscular fat from steers offered grazed grass, grass silage or concentrate based diets. Journal of Animal Science, v.78, n.11, p.2849-2855, 2000

FOX, D.G.; SNIFFEN, C.J.; O’CONNOR, J.D. et al. A net carbohydrate and protein system for evaluating cattle diets. III. Cattle requirements and diets adequacy. Journal of Animal Science, v.70, n.11, p.3578-3596, 1992.

GREGORY, N.G. Animal welfare and meat science. Cambridge: University Press, 1998. 289p.

HAMM, R. Functional properties of the myofibrilar system and their measurement. In: BECHTEL, P.J. (Ed.) Muscle as food. Orlando: Academic Press, 1986. p.135-199.

HOUBEN, J.H.; Van DIJK, A.; EIKELENBOOM, G. et al. Effect of dietary vitamin E supplementation, fat level and packaging on color stability and lipid oxidation in minced meat. Meat Science, v.55, n.3, p.331-336, 2000.

LAWRIE, R.A. Ciência da carne. 6.ed. Porto Alegre: Artmed, 2004. 384p.

MALAU-ADULI, A.E.O.; SIEBERT, B.D.; BOTTEMA, C.D.K. et al. A comparison of the fatty acid composition of tryacilglycerols in adipose tissue from Limousin and Jersey cattle. Australian Journal of Agriculture Research, v.48, n.5, p.715-722, 1997.

MANSBRIDGE, R.J.; BLAKE, J.S. Nutritional factors affecting the fatty acids composition of bovine milk. British Journal of Nutrition, v.78, p.37-47, 1997 (suppl. 1).

MIR, P.S.; IVAN, M.; HE, M.L. et al. Dietary manipulation to increase conjugated linoleic acids and other desirable fatty acids in beef: a review. Canadian Journal of Animal Science, v.83, n.4, p.673-685, 2003.

PADRE, R.G.; ARICETTI, J.A.; MOREIRA, F.B. et al. Fatty acid profile, and chemical composition of Longissimus muscle of bovine steers and bulls finished in pasture system. Meat Science, v.74, n.1, p.242-248, 2006.

RESTLE, J.; CERDOTES, L.; VAZ, F.N. et al. Características de carcaça e da carne de novilhas Charolês e 3/4 Charolês 1/4 Nelore, terminadas em confinamento. Revista Brasileira de Zootecnia, v.30, n.3, p.1065-1075, 2001 (supl. 1).

RUBENSAM, J.M.; FELÍCIO, P.E.; TERMIGNONI, C. Influência do genótipo Bos indicus na atividade da calpastatina e na textura 
da carne de novilhos abatidos no sul do Brasil. Ciência e Tecnologia dos Alimentos, v.18, n.4, p.405-409, 1998.

SAMPAIO, I.B.M. Estatística aplicada à experimentação animal. 2.ed. Belo Horizonte: Fundação de Estudos e Pesquisas em Medicina Veterinária e Zootecnia, 2002. 265p.

STATISTICAL ANALYSIS SYSTEM - SAS. User's guide. Cary: SAS Institute, 2001. (CD-ROM).

SCOLLAN, N.; HOCQETTE, J.F.; NUERNBERG, K. et al. Innovations in beef production systems that enhance the nutritional and health value of beef lipids and their relationship with meat quality. Meat Science, v.74, n.1, p.17-33, 2006.
TULLIO, R.R. Estratégias de manejo para produção intensiva de bovinos visando à qualidade da carne. 2004. 107f. Tese (Doutorado em Zootecnia) - Faculdade de Ciências Agrárias e Veterinárias, Universidade Estadual Paulista, Jaboticabal, 2004. WOOD, J.D.; RICHARDSON, R.J.; NUTE, G.R. et al. Effects of fatty acids on meat quality: a review. Meat Science, v.66, n.1, p.21-32, 2003.

ZEMBAYASHI, M.; NISHIMURA, K.; LUNT, D.K. et al. Effects of breed type and sex on fatty acid composition of subcutaneous and intramuscular lipids of finishing steers and heifers. Journal of Animal Science, v.73, n.11, p.3325-3332, 1995. 